\title{
Design of Cylindrical Shape Microstrip-Fed Antenna at 2.45 GHz for RFID Applications
}

\author{
Leeza Bansal \\ M.Tech. Scholar \\ HCTM, Kaithal
}

\begin{abstract}
In this paper, a monopole antenna based on microstrip-fed for RFID frequency is proposed. The given antenna is composed of a cylindrical patch. The antenna exhibits single band, which creates an impedance bandwidth of $0.32 \mathrm{GHz}$. The research, simulation and design of single band antenna operates at $2.45 \mathrm{GHz}$. The fundamental parameters such as return loss, gain, radiation pattern, current distribution are obtained. A parametric study of proposed antenna has been carried out by varying some parameters. Simulation tool, based on method of moments has been used to analyze and optimize the antenna.
\end{abstract}

\section{Keywords}

Radio frequency identification (RFID), Microstrip line, Cylindrical Patch

\section{INTRODUCTION}

In recent years, RFID has been widely used in service industries as an automatic identification tool [1]. A basic RFID system comprises a radio-scanner unit, called reader, and a set of remote transponders, denoted as tags, which include an antenna and a microchip transmitter with internal $\mathrm{read} /$ write memory $[2,3]$. Several frequency bands have been standardized for this technology, low frequency (LF, 125-134 $\mathrm{kHz})$, high frequency $(\mathrm{HF}, 13.56 \mathrm{MHz})$, ultra-high frequency (UHF, $860-960 \mathrm{MHz})$ and microwave $(2.45 \mathrm{GHz}$ and $5.8 \mathrm{GHz}$ ). The systems using the UHF band and $2.45 \mathrm{GHz}$ band are believed suitable for long-distance communication utilizing a passive type RFID [5, 6]. However, because the UHF band overlaps with the frequency of a cellular phone, the UHF band is not preferable. Therefore, the $2.45 \mathrm{GHz}$ band is preferred [4].

Several papers have been published on designing RFID antennas [7-10]. In [7], a miniaturized printed dipole antenna with the V-shaped ground is proposed for RFID readers operating at the frequency of $2.45 \mathrm{GHz}$. A compact folded printed dipole antenna for UHF RFID reader is presented in [8].

A dualband antenna RFID tag is presented in [9] that allow operation in the $900 \mathrm{MHz}$ band as well as in the $2.45 \mathrm{GHz}$ band. In [10], a triple band printed dipole tag antenna is proposed for RFID. The triple band printed dipole is designed to operate at $0.92 \mathrm{GHz}, 2.45 \mathrm{GHz}$ and $5.8 \mathrm{GHz}$. Several papers have been published on RFID antennas for both active and passive tags. At the same time, there exist many papers on practical analysis and design of particular classes of antennas used for other applications $[11,12]$.

\author{
Davinder Parkash \\ Assoc. Prof. ECE Dept. \\ HCTM, Kaithal
}

In this paper, a cylindrical shaped antenna is presented which covers $2.45 \mathrm{GHz}$ band which is the operating band of RFID application. The details of the proposed antenna design and the simulated results are presented and discussed next.

\section{ANTENNA DESIGN}

A cylindrical shaped patch is designed for the RFID (2.45 $\mathrm{GHz}$ ) frequency range and placed on a conventional ground plane. The geometry of the proposed antenna is shown in Figure1. The total size of the proposed antenna is $23.1 \mathrm{~mm} \mathrm{x}$ $45 \mathrm{~mm}$. As shown in the Figure, the antenna consists of a cylindrical patch. The antenna mainly constructed with the above described patch and fed by microstrip feeding. The total size of this antenna with ground plane is $31.6 \mathrm{~mm} \mathrm{x} 45 \mathrm{~mm} \times$ $1.6 \mathrm{~mm}$. The ground plane is symmetrical at the base line of the feeding strip line. The size of cylindrical patch is adjusted to obtain optimum bandwidth. To obtain the optimal parameters of the proposed antenna for RFID application, IE3D, full-wave commercial EM software that can simulate a finite substrate and a finite ground structure, is used. By properly adjusting the dimension of antenna and feeding structure the characteristics of the proposed antenna is improved. Figure 1 shows the geometry of proposed antenna. In which (a) part presents the complete geometry and (b) part presents the back view that is ground of the microstrip patch antenna.

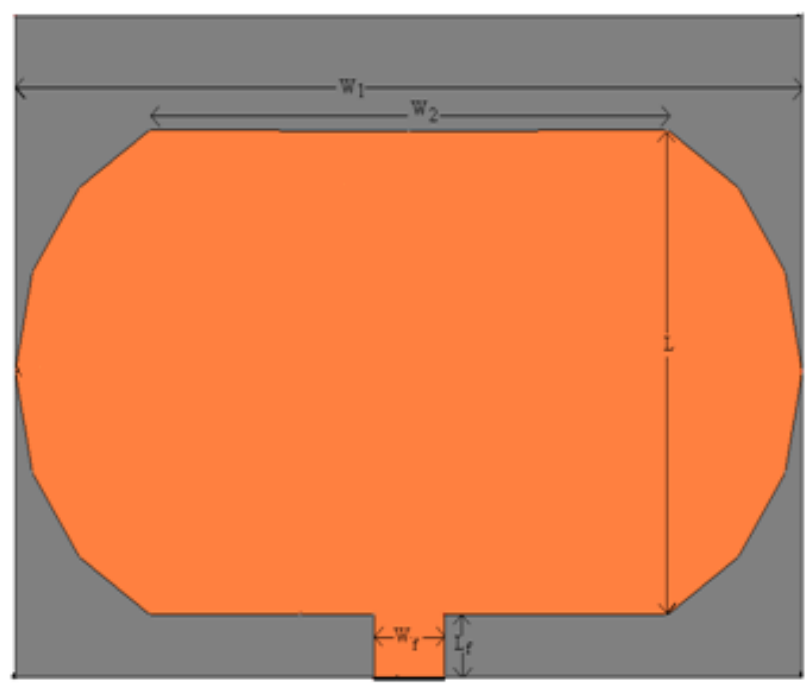




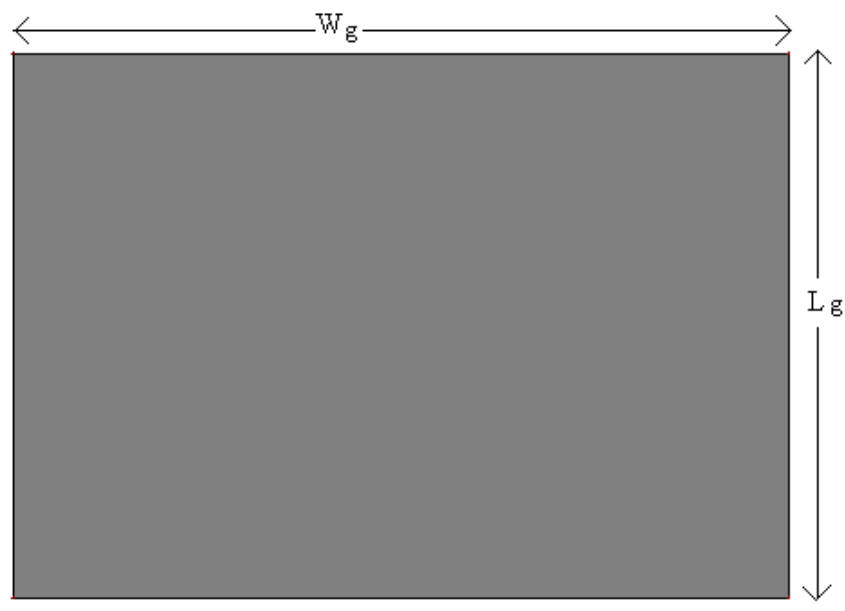

Figure 1: (a) Front View of proposed antenna (b) Back View

The optimized dimensions of antenna are set as follows:

Table 1: Parameters of the proposed antenna

\begin{tabular}{|c|c|}
\hline Parameter & $\begin{array}{c}\text { Dimensions } \\
\text { (in mm) }\end{array}$ \\
\hline $\mathrm{L}$ & 23.1 \\
\hline $\mathrm{W}_{1}$ & 45 \\
\hline $\mathrm{W}_{2}$ & 29.55 \\
\hline $\mathrm{L}_{\mathrm{g}}$ & 31.6 \\
\hline $\mathrm{W}_{\mathrm{g}}$ & 45 \\
\hline $\mathrm{L}_{\mathrm{f}}$ & 3.025 \\
\hline $\mathrm{W}_{\mathrm{f}}$ & 4 \\
\hline
\end{tabular}

The feeding is provided by the rectangular strip of dimensions $3.025 \times 4 \mathrm{~mm}^{2}$ in the proposed antenna. With the aid of simulation by IE3D Simulator which is based on the method of moment (MOM), the antenna is optimized. The details of simulated performance are described briefly in next section.

\section{SIMULATION RESULTS AND DISCUSSIONS}

The design evolution of the proposed antenna and its corresponding simulated return losses are presented in Figure 2. It shows the simulated results of the proposed optimised antenna, which are in a good agreement. The band has a -10 $\mathrm{dB}$ impedance bandwidth of $320 \mathrm{MHz}(2.28-2.6 \mathrm{GHz})$ for the simulated results.

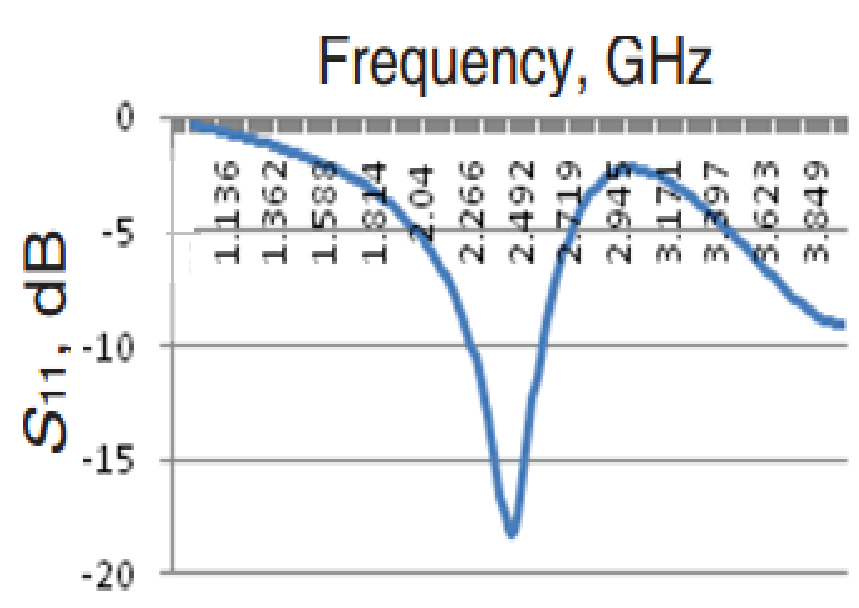

Figure 2: Return loss of proposed antenna

It has been examined that proposed design covers the RFID band from $2.28-2.6 \mathrm{GHz}$.

Fig 3 shows the VSWR of proposed antenna. VSWR of 1.27 is obtained at $2.46 \mathrm{GHz}$.

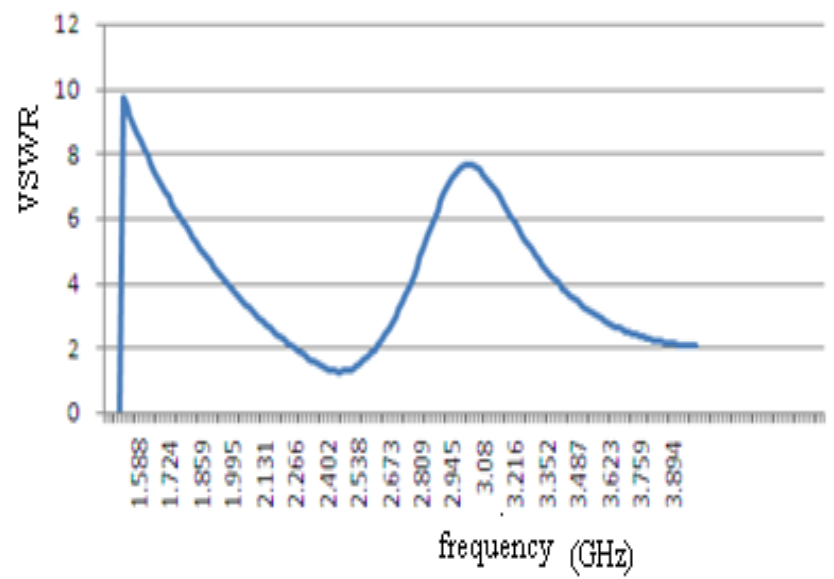

Figure 3: VSWR of proposed dual band antenna In figure 4 , the current distribution pattern shows that how much of the current is flowing in the proposed structure. Maximum current in the proposed antenna is 5.8376 at 2.46 GHz. The 3D current distribution plot gives the relationship between the co-polarization (desired) and cross-polarization (undesired) components. It gives a clear picture as to the nature of polarization of the fields propagating through the patch antenna. 


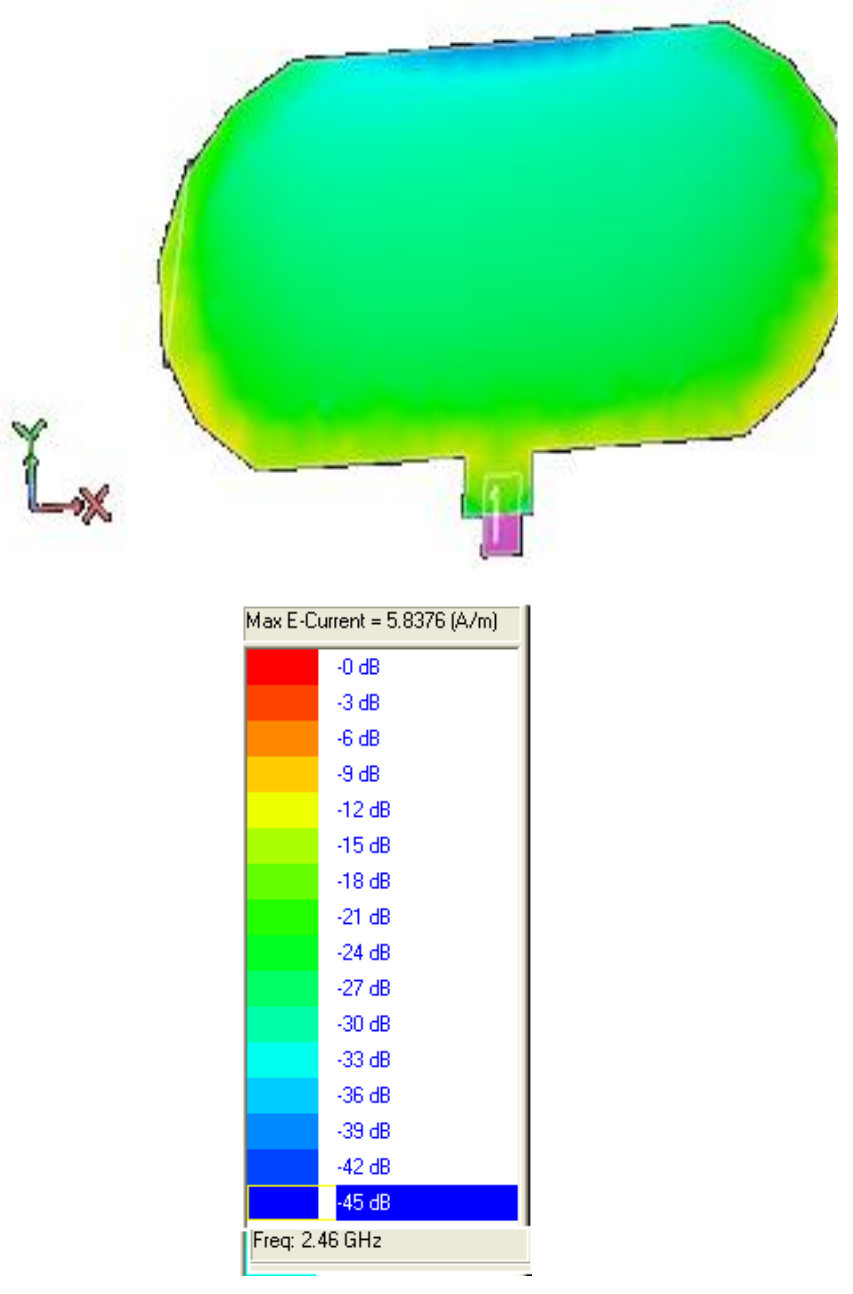

Figure 4: Current Distribution of proposed antenna at $2.46 \mathrm{GHz}$

In figure 5(a) and 5(b) simulated 2D radiation pattern for elevation and azimuthal plane at resonant frequency $2.46 \mathrm{GHz}$ is shown. These patterns are desirable for RFID applications. Radiation pattern presents the graphical representation of radiation properties of antenna as a function of space coordinates .Three dimensional radiation pattern is obtained by combining elevation pattern and azimuth pattern. Figure 6 shows three dimensional radiation pattern of proposed antenna.

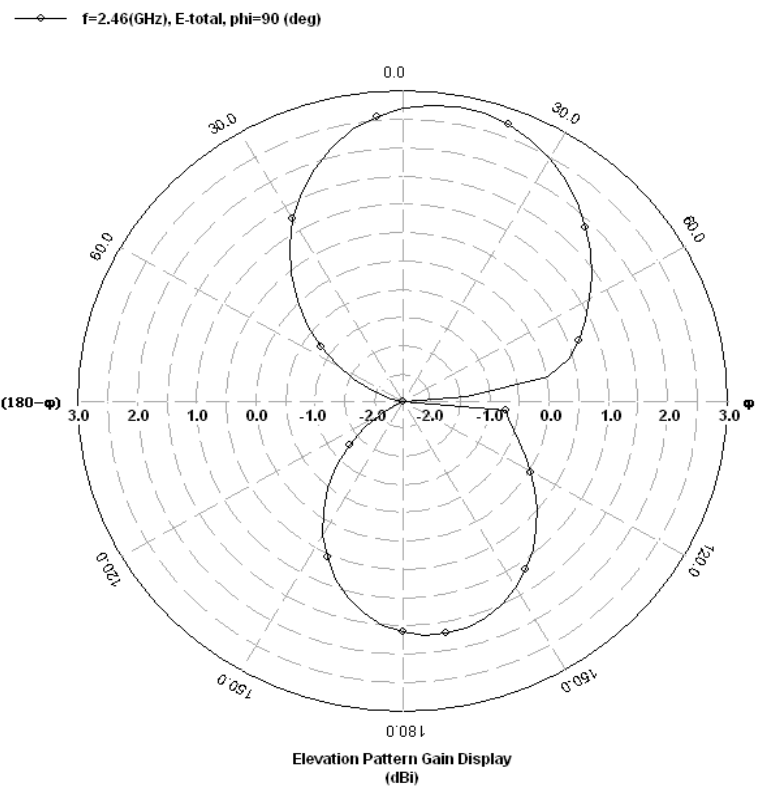

Figure 5(a): Elevation pattern at $2.46 \mathrm{GHz}$

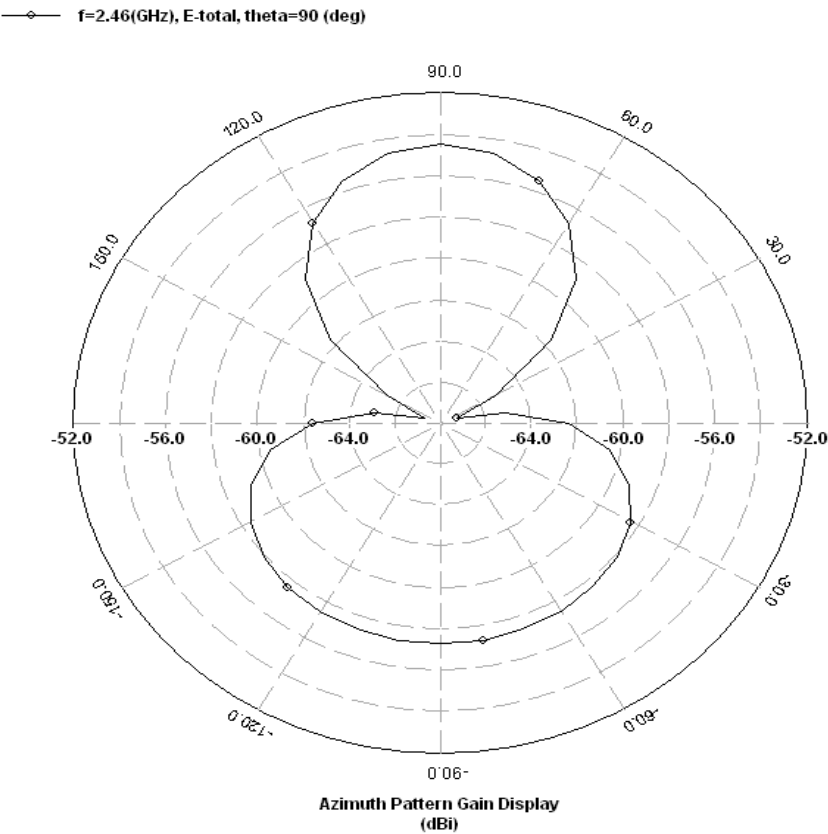

Figure 5(b): Azimuth pattern at $2.46 \mathrm{GHz}$ 


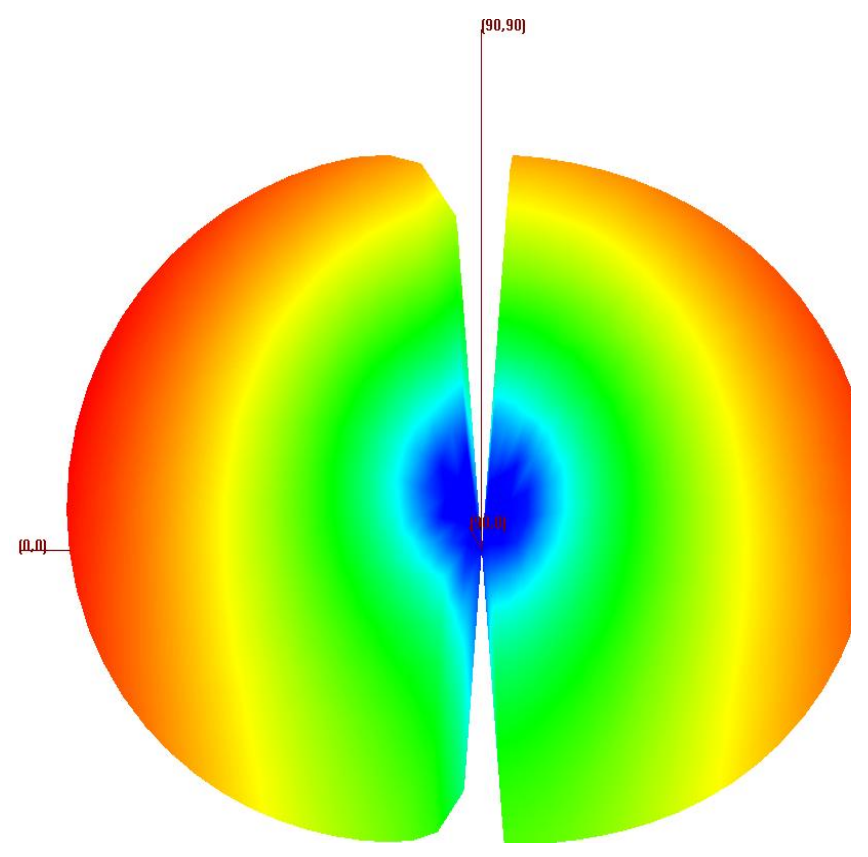

Figure 6: 3-Dimensional Pattern of Proposed Antenna

\section{PARAMETRIC STUDY}

Figure 8 shows the parametric study of the proposed antenna. It demonstrates that many parameters affect the performance of the proposed antenna. The parametric study is carried out by simulating the antenna with one geometry parameter slightly changed from the reference design while all the other parameters are fixed. The parametric study showing the case when patch width is decreased, there was no impedance bandwidth in working bands but return losses are more than $10 \mathrm{~dB}$. Also when feed length is increased then again there was no impedance bandwidth in working bands.

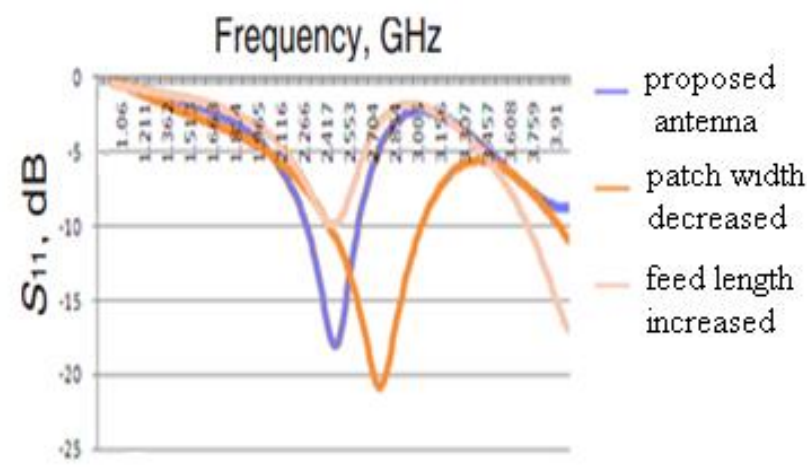

Figure 8: Parametric comparison of return loss of antenna

\section{CONCLUSION}

A design of microstrip fed monopole antenna for RFID tag applications has been proposed. It covers RFID band from 2.28-2.6GHz. A single band operation has been obtained and good radiation characteristics have been observed at 2.46 GHz. The proposed antenna has been designed and simulated for resonant frequency at $2.46 \mathrm{GHz}$. Effects of varying dimensions of key structure parameters on the antenna and various parameters like gain, VSWR, current distribution, radiation pattern and their performance are also studied. These characteristics are very attractive for some wireless communication systems for a variety of applications.

\section{REFERENCES}

[1] K. Finkenzeller, RFID Handbook: Radio- Frequency Identification Fundamentals and Applications, $2^{\text {nd }}$ Ed., John Wiley \& Sons, Inc., New Jersey, USA, 2004.

[2] www.intechopen.com/download/pdf/8994.

[3] eprints.ibu.edu.ba/1058/1/vol1-no1-p53-71.pdf.

[4] Jin, A., S. Takahashi, and K. Shimamura, "A basic study on communication capability of $2.45 \mathrm{GHz}$ band RFID tag and communication quality with a reader," Proceedings of Int. Con-ference on Next Era Information Networking, NEINE, 330-335, Kochi-city, Japan, Sep. 26-27,2004.

[5] Curty, J.-P., M. Declercq, C. Dehollain, and N. Joehl, Design and Optimization of Passive RFID System, Springer, New York, USA, 2007.

[6] Z. N. Chen, Antennas for Portable Devices, John Wiley \& Sons Ltd, England, 2007.

[7] Fan, Z., S. Qiao, H. F. Jiang Tao, and L. X. Ran, "A miniaturized printed dipole antenna with V-shaped ground for $2.45 \mathrm{GHz}$ RFID readers," Progress In Electromagnetics Research, Vol. 71,149-158, 2007.

[8] Li, X., L. Yang, S.-X. Gong, Y.-J. Yang, and J.-F. Liu, "A compact folded printed dipole antenna for UHF RFID reader," Progress In Electromagnetics Research Letters, Vol. 6, 47-54,2009.

[9] Tran Minh Tuan, "Design dual band microstrip antenna for RFID application" VNU Journal of Science, Natural Sciences and Technology 26 (2010) 276-280.

[10] M. Abu and M. K. A. Rahim, "Triple-Band Printed Dipole Tag Antenna for RFID” Progress In Electromagnetics Research C, Vol. 9, 145-153, 2009.

[11] G. Bulla, M. T. Le, A. A. A. de Salles and T. P. Vuong, "Miniaturized Printed Yagi Antenna for $2.45 \mathrm{GHz}$ RFID Readers" PIERS Proceedings, Marrakesh, MOROCCO, March 20-23, 2011.

[12] Mahmoud, K. R., "Design optimization of a bow-tie antenna for $2.45 \mathrm{GHz}$ RFID readers using a hybrid BSONM algorithm," Progress In Electromagnetics Research, Vol. 100, 105-117, 2010. 